\title{
Reducing teacher stress and burnout in high-risk secondary schools in South Africa using transactional analysis
}

(C) 2015 Sharon Mary Johnson

\begin{abstract}
One of a number of articles arising from $P h D$ research, this paper focuses on the results of applying transactional analysis as one of three approaches to reducing stress and burnout for teachers in high-risk secondary schools in the gangland areas of the Cape Flats, Western Cape, South Africa. The other approaches were Trauma Release Exercises (TRE) and Transpersonal Psychology (TP), and related articles on these and on the quantitative statistical analysis elements of this research are being disseminated elsewhere.
\end{abstract}

A total of 43 teachers in three different schools took part in one intervention held weekly over 10 weeks for one and a half hours (15 hours in total) at their school as part of staff development, with a control group of 20 teachers at a fourth school. Qualitative TA intervention questionnaire coding analysis and focus group post-intervention thematic analysis of the mixed-methods study are presented. Coding analysis focused on the intra- and inter-individual tools that impacted teachers, and it was found that TA generated self-awareness, self-help tools and a strong group connection. Thematic analysis gave insights into the physical, emotional and cognitive responses to stress and burnout interventions on the individual, interpersonal and organisational levels and revealed new perspectives on classroom competency, with teachers taking more responsibility for discipline in the classroom.

The study gave insights into the well-being and coping of educators who survive in these challenging contexts, and it is proposed that TRE, TP and TA approaches can be incorporated, and possibly combined, into integrative and eclectic ways of dealing with complex psychological challenges of stress and burnout reduction in traumatic environments.

\section{Key words}

Stress and burnout interventions; transactional analysis, coding analysis, thematic analysis, classroom discipline, school violence.

\section{Introduction}

There has been a plethora of educational policies in South Africa over the past 20 years to address the democratisation of schools, in line with the dismantling of apartheid and social transformation (Waghid \& Davids, 2013). Unfortunately, the practices implemented by these policy statements have had little impact on the reality in the classroom in many high-risk schools. Violence and lack of student discipline are among key factors which have eroded academic standards steadily over the past 20 years, resulting in what has been described as an educational crisis in the country (Jansen, 2012). The majority of teachers suffer from stress and burnout in an effort to fulfil their pedagogical obligations (Johnson, 2013; Johnson \& Naidoo, 2010). This paper considers transactional analysis as a means to reduce teacher stress and burnout.

\section{Schools Context}

Declining educational standards in South Africa are of national concern, with revision of matric schoolleaving requirements by government (Capazorio \& Thakali, 2012). While progress has been made for the poor in South Africa since democracy 19 years ago, with access to roads, electricity, potable water and services that were denied to black people under apartheid, they have been denied the most important tool for empowerment - education (Hartley, 2012). He describes how those who have made it through the schools struggle to find places in the universities; those who have made it through university can find no place in the job market.

A broader move towards devaluing education in South Africa is leading to social and educational 
illiteracy, where emotions triumph over logic, where reason is displaced by wrath and where books take second place to rocks (Jansen, 2012). As there are no short cuts to changing society, he suggests that a social revolution that once again places education at the centre for change needs to take place, where ordinary people confront the rot in the school system before it is too late. A proposal by President Jacob Zuma in the 2013 State of the Nation address to make education an essential service came with the assurance that teachers would not be denied their constitutional right to strike. A presidential remuneration commission has been set up to investigate salaries and working conditions of teachers (Munusamy, 2013).

Schools on the Cape Flats, for example, lack essential facilities for sports and recreation and even basic infrastructure is missing, such as school fences and water pipes, which are often vandalised or stolen. There are broken windows, gaping holes in ceilings, barren concrete school grounds, with main entrances and even school classrooms having heavy security gates, in an effort to keep children in school and criminals out. Schools are faced with severe resource limitations, with one psychologist and one social worker attending to the psychosocial needs of approximately 100,000 children in a district metro (Jalamba, 2009).

Teacher Stress and Burnout

Teaching is emotionally and physically demanding, with stress symptoms including isolation resulting from working alone in the classroom and scheduling constraints which make meeting time with peers difficult, role conflict and role ambiguity, sense of powerlessness, and both physical and mental exhaustion (Wood \& McCarthy, 2002). These symptoms can lead to burnout with individual characteristics, as well as job-related stressors being important contributors (Kokkinos, 2007). The structural and organisational challenges faced by the Western Cape Education Department (WCED) are great, with the legacy of apartheid still being evident in high-risk communities.

A study by the Human Sciences Research Council (2005) found $10.6 \%$ of teachers in South Africa had been hospitalised in the previous 12 months (Johnson, 2010). Another indication of educators' health status was that at least $75 \%$ had reported a visit to a health practitioner in the six months before the study. The most frequently reported diagnoses in the last five years before the study were stressrelated illnesses, such as high blood pressure $(15.6 \%)$, stomach ulcers $(9.1 \%)$ and diabetes $(4.5 \%)$.
In early 2013 South Africa was reported as having the highest absenteeism rate of teachers in the Southern African Development Community - a total of $7,448,000$ days was lost in 2012 , or 19 days on average per teacher, which is double the rate of other neighbouring countries (South African Press Association, 2013).

South African research has found that teachers need emotional-social competencies to cope: empathy, optimism, assertiveness, self-awareness, realitytesting, social responsibility, flexibility, impulse control and stress tolerance (Van Wyk, 2006). To relieve pressures which could lead to stress and burnout, training in emotional-social competencies was recommended. In a study of the role played by hardiness and attributional style in the dynamics of stress and coping processes, it was found that South African teachers who are high in hardiness generally use more transformational coping than subjects lower in hardiness (Leon, 2000). It was also found that subjects high in commitment, a sub-component of hardiness, were more likely to have an internal locus of control. Stronger coping mechanisms, communication skills, interpersonal relationships, emotional security, intellectual stimulation and a balance between professional and personal satisfaction were additional factors found to help teachers to feel better. Gold and Roth (2003) offer a professional health solution for teachers, which considers physical-emotional, psycho-social and personal-intellectual well-being.

Due to complex social and political events, traumatic experiences have increased in everyday life, creating new challenges for mental health practitioners dealing with trauma and its aftermath (Ringel \& Brandell, 2011). While these authors cite the 9/11 attacks, war on terror, combat trauma and school shootings as a result of bullying as contemporary American traumas, traumatologists in South Africa are faced with challenges such as intergenerational trauma resulting from political injustices and continuous trauma on the Cape Flats as the result of multiple on-going factors, such as violence and poverty (Kaminer \& Eagle, 2010).

\section{Coping and Well-being}

The relationship between stress and the onset of burnout may depend on an individual's coping strategies (Wilkerson, 2009). Coping has been defined "as constantly changing cognitive and behavioural efforts to manage specific external and/or internal demands that are appraised as taxing or exceeding the resources of the person," (Lazarus \& Folkman, 1984, p. 141). This definition is more process than task-orientated, distinguishing 
between coping and automised behaviour which limits coping to conditions of psychological stress, and focuses on efforts to manage stress, regardless of outcome. Coping is not identified with mastery in this definition, but includes efforts to minimise, avoid, tolerate or accept stressful conditions.

Well-being, or wellness, has also been described as an evolving rather than static state. "High-level wellness involves giving good care to your physical self, using your mind constructively, expressing your emotions effectively, being creatively involved with those around you, and being concerned about your physical, psychological, and spiritual environments." (Travis \& Ryan, 2004, p. xix)

Little attention, however, has been paid to the potential impact of coping strategies on physical health and well-being of individuals (Dewe et al., 2010), with almost all studies on coping focusing on psychological strain or distress. Day and Livingstone (2001), cited in Dewe et al. carried out research with "intriguing results" (p. 93) when studying selfreported health symptoms among military personnel. Only negative coping styles, such as venting of emotions, denial and disengagement, exacerbated rather than alleviated health problems. Positive coping strategies, such as problem-solving and seeking informational and emotional support, had no physical effects on health complaints. Considering the relationship between trauma and resilience, McElheran (2013) questions whether well-being and happiness are part of a Western myth that if we do not feel happy, then something is wrong. She focuses instead on the development of character through effort and pain and suggests that the struggle to emerge is crucial to transformation.

\section{Research Question and Rationale}

The research question predicating this study is: How do interventions, based on trauma release exercises, transpersonal psychology and transactional analysis, impact stress and burnout of educators in high-risk secondary schools? In answering this question, the influence of these interventions on stress, burnout, coping and well-being of educators and their effect on classroom competency, were considered.

Levels of educator stress and burnout were established, positive and negative factors about the interventions were elicited and possible areas of improvement in training uncovered. The research sought to gain insight into the life-worlds of these teachers, assess whether TRE, TP or TA interventions affected stress and burnout, and how teachers' experiences impacted on their coping and well-being. If professionals, such as teachers, can benefit from practices in alleviating stress and preventing burnout, their physiological, affective and cognitive responses should improve.

Potential health consequences in the long term are broad, including the reduction of absenteeism due to sick leave, less susceptibility to infection and reduced resignations due to burnout. Practically, if TRE, TP and TA provide effective tools for mediating stress and burnout, a new model combining some or all of these techniques could be consolidated and further assessed in South African schools in future. Notwithstanding which intervention they received, educators could gain skills to deal with on-going stress and challenges of life.

Theoretical Approach

The main theoretical challenge of this study was to combine evolutionary understandings of brain development with current neurological research into brain function and make these insights relevant to community interventions. The aim was to facilitate meaningful engagement with stress and burnout interventions in group efforts with teachers to improve traumatic social conditions in schools in the ganglands of Western Cape, South Africa. The interventions designed for this challenging context of high learner to educator ratios, high number of learners per school and inadequate number of educators per school, were based on the three brain model (Cummings \& Mega, 2003; MacLean, 1990; Yakovlev \& Lecours, 1967). In this study, the phylogenetic, anatomic and functional aspects of the brain were considered in designing interventions aimed at reducing stress and burnout: TRE engages the reptilian, survival brain; TP, the paleomammalian, emotional brain and TA, the neomammalian, rational brain.

The first intervention was body-based, involving TRE, developed by Berceli (2007), who was invited to South Africa in 2009. He heads an international trauma organisation, operating in over 30 countries around the world. The second intervention is transpersonal in emphasis, based on the work of Cane (2000), who is founder and director of Capacitar International, a world-wide movement, established in 1988, involved in trauma healing and transformation. More details on these interventions can be found in Johnson (2013).

The third intervention (TA) is based on the rational brain, drawing on Eric Berne's clinical observations as a psychotherapist in the 1970s, with psychodynamic principles checked directly in real world observations (Stewart, 1992). Berne is described by Stewart as the first psychodynamic theorist to make observability the cornerstone of the entire theory. In considering the transactional model of stress in this study (Lazarus \& Folkman, 1984), 
Berne's transactional analysis of relationships provides a theoretical basis for the understanding of stressful transactions between educator and learner and subsequent coping strategies.

Intervention Design

All three stress and burnout intervention workshops in this study focus on stressors and coping strategies of educators, with major goals being to develop positive attitudes and improved interpersonal skills. The three interventions used group process to facilitate change; and sought to help participants transfer what is learnt to everyday challenges in the classroom and in life. By mirroring challenges faced in the classroom, the workshops aimed to help teachers with daily struggles.

Overall, the researcher planned the workshops, with practical input from trainers who assisted the researcher to understand and apply key concepts, and facilitators who ran the workshops for teachers in the schools. The main focus was on large-group discussion, with inter- and intra-personal processing. Theoretically and practically the researcher had worked with and trained in TRE, TP and TA for several years in diverse contexts, mindful of how each theoretical model presented to educators could assist them to understand educational challenges in traumatic contexts. Alex van Oostveen, who is a TA educational trainee, facilitated the TA workshops with material designed by him, under the guidance of the researcher as well as Karen Pratt, a Training Transactional Analyst (TTA) and Provisional Supervising Transactional Analyst (PSTA) with a specialisation in education. Participants received detailed training notes printed for each session.

Group 1 teachers $(n=17)$ were exposed to TRE, which facilitates somatic release of tension and stress with neurogenic tremors; Group 2 were teachers $(n=16)$ who experienced emotional processing and healing with TP, and Group $3(n=10)$ participated in TA workshops, which utilised social psychology for greater understanding between learners and educators inside the classroom.

Psycho-educational Model

The intervention models of TRE, TP and TA are based on psycho-education, which is a major conceptual model in education, especially relevant for community mental health treatment groups (Holtzkamp, 2010). While a feature common to all three interventions was the focus on stress and burnout in the school context of the Cape Flats, intrapersonal as well as interpersonal processes were central to this study. In workshop design, the importance of self-reflection in the context of a psychological sense of community, addressing educator concerns with cognitive, emotional or physiological support, combined with social support, were underlying principles. Whatever the intervention, the group workshop format promoted collaboration and mutual support among delegates. Indeed, groups have power to move people in creative and life-giving directions (Corey, Corey \& Corey, 2010).

Psychological insights and practices facilitated in psycho-educational group interventions for stress and burnout could contribute to healing in sustainable and creative modes of reflective living in high-risk communities, including schools. The trauma prevalent in high-risk schools has a profound effect on those endeavouring to carry out their professional obligations as educators. Dissociated imprints of traumatic experience, such as physical sensations, panic, and helplessness, can be overwhelming, but ignoring or repressing unpleasant, painful sensations and feelings generally makes things worse (Van der Kolk, 2007). In considering the plight of teachers in the challenging gangland context of the Cape Flats, Western Cape, South Africa, this study aimed to provide interventions for teachers to move from avoidance and helplessness to renewed energy and focus, offering a self-supporting, self-managed context to better cope with situations that once felt overwhelming.

\section{Ethical Considerations and Funding}

The need to protect the rights and privacy of teachers was considered, as well as their vulnerability, given the focus of the study on stress and burnout. Referral options in the case of adverse reaction were given. Participants gave signed informed consent, with anonymity being assured. Participants had the right to withdraw from the study at any time, without negative consequences. Confidentiality of test scores and interview data was assured and material was stored in a safe and inaccessible place off the school premises, with password protected computer access. Ethical clearance was given from the Ethics Committee of Stellenbosch University, as well as from the Western Cape Department of Education, and letters of permission from all school principals were obtained.

Dr Johnson received the Prestige Equity Award funding from South Africa's National Research Foundation for her $\mathrm{PhD}$ (2012-2014) and is receiving further funding to co-create trauma-informed educational milieus with teachers, staff and school principals in a high-risk school and a child care centre in the ganglands of the Western Cape, South Africa. 


\section{Research Process}

The impact of three stress and burnout interventions on high school educators was analysed with a mixedmethods concurrent strategy to employ the best methods that serve the theoretical perspective of the researcher. By using two phases - quantitative data with pre- and post-intervention statistical analysis of stress, burnout and well-being measures (Johnson, 2013) and qualitative coding text analysis and thematic analysis of focus group interviews - the researcher aimed to consider diverse perspectives, to better advocate for participants, and to improve understanding of the change process as a result of being studied.

\section{Participants}

Because of the logistical constraints such as differing timetables at the schools, random assignment of participants to intervention groups was not feasible. Interventions were randomly assigned to schools, depending on the availability of teachers and facilitators. Most workshops took place from 14h30 for an hour and a half on a Tuesday, Wednesday or Thursday, with two interventions, TP and TA, taking place at the same time, which limited the number of workshops attended by the researcher. In all instances the researcher provided tea and ensured materials were printed and that facilitators were wellprepared.

Both sexes were almost equally represented in total in all groups (men, $n=32$; women, $n=31$ ). However, group distribution varied, with two groups (TRE and TP) having a majority of women, and two groups control and TA, having more men. Most participants were married $(n=48 ; 76 \%)$, with a few single, divorced or widowed. Overall, teachers were Christian ( $n=41 ; 65 \%$ ) with most others being Muslim. In most groups, the majority of teachers were aged between 40 and 50 . The TA intervention had older participants, with $40 \%$ of teachers over 50 . Most teachers participating had been involved in teaching for between 20 and 30 years ( $n=29 ; 46 \%)$, with $8 \%(n=5)$ of participants teaching for over 30 years in the TRE and control groups. A small number of educators $(n=10 ; 16 \%)$ had taught for less than 10 years, with $50 \%(n=5)$ being in the control group.

Key TA concepts

With its focus on transactions between people, TA offers a relevant approach to the dealing of stress in Lazarus and Folkman's (1984) transactional model. Despite highly intellectual concepts, its strength is in its practicality and rationality, which can be understood by all ages and mental abilities (Talob, 1994). Talob urges future studies to examine TA as a dynamic process, not just a fixed body of knowledge or a mere theory of personality. It is indeed the aim of this study to focus on the practical process strengths of this theoretical functional model.

Philosophical assumptions of TA are about people and their interactions: people are OK; everyone has the capacity to think; people decide their own destiny and these decisions can be changed (Berne, 1961). From these assumptions follow two basic principles of TA practice: the contractual method and open communication, which underlie workshop interventions in this study. Key TA concepts relevant to human interactions chosen in this study are setting up contracts (Berne, 1966), functional ego states (Berne, 1972), transactions and games (Berne, 1964), life positions (Berne, 1962), and the drama triangle (Karpman, 2007). Other TA concepts presented in workshops were: stroke theory (Steiner, 1971; McKenna, 1974), drivers (Kahler \& Capers, 1974) and working styles (Hay, 2009)

\section{Methodology}

Coding analysis. Content analysis of stress, emotional responses, classroom competency and coping followed the steps suggested by Silverman (2011), based on the work of Bauer (2000) and Marvasti (2004). It is recommended that particular texts are selected relevant to the research problem. A workshop assessment questionnaire asking for response to the intervention and an appreciative selfinquiry questionnaire, seeking reflection of stressors and ways of coping over the previous week, were used as text for content analysis. As these questionnaires were voluntary, not all teachers filled them in every time. Some educators took them home to reflect upon, and returned them during the course of the following week. Most workshop questionnaires were filled in regularly, but some educators only reflected on their stressors and coping strategies at the start, middle and end of the interventions. As a small sample of teachers participated in each intervention ( $n=10$ to $n=17)$, the amount of data was deemed manageable.

A coding frame (categorisation scheme) was then constructed to fit both the theoretical considerations and the materials. The codes were tested for ambiguities and all materials in the sample were coded, establishing the reliability of the process as much as possible. A data file was then set up for the purposes of statistical analysis. Both the rationale of the coding frame and frequency distribution of all codes are given with reliability of the coding process.

While this method is described by Marvasti (2004) as convenient in simplifying large amounts of text into organised segments, fitting data into operationalised predetermined categories, rather than the participants' interactional deployment of categories, 
renders the theoretical base unclear and conclusions drawn could be considered trite (Silverman, 2011). In listing codes, the researcher illustrated with brief extracts from participants to better describe the meaning of the code. For example, under the theme, Stressors and the code, Societal Problems, the quotation "Suffering children" gives greater understanding

Focus group thematic analysis: This method offers breadth, describing a "substantive phenomenon” (Silverman, 2011, p. 213). Qualitative data were collected in focus group interviews of all participating educators in each intervention, with a follow-up session during which themes were checked, confirmed and amended where necessary.

In this study, a psychological perspective of educator stress and burnout was examined in the cultural context of the Cape Flats area of Cape Town, South Africa. Teachers were given a voice to describe not only the context of their personal and professional lives, but also the impact of a stress and burnout intervention on their coping, well-being and understanding of competency in the classroom. In each intervention session, teachers were given the opportunity for group sharing about their stress and burnout and methods and procedures presented were linked directly to classroom experiences and competency.

At the end of the interventions, focus group discussions provided data generated via group interaction, building conversation among participants (Millward, 2012). It is this element of interaction that enables the elicitation of a different type of evidence not possible from a one-to-one interview (Morgan, 1997). Group dynamics are managed by an external moderator, who ensures discussion occurs in a focused way. Conversation becomes owned by participants when they are excited by the topic and pursue the discussion in an animated way which has its own meaningful direction. For Morgan (1997), the full potential of focus groups as a psychological tool is starting to be recognised, although this tends to be more said than done. The balance between covering the topic adequately and allowing the information to flow freely requires great skills of facilitation (Millward, 2012).

Reliability. Reliability concerns the assessment of the measurement technique or strategy employed (Hammersley, 1990). Reliability of focus group data requires conducting a systematic analysis of the transcripts or tapes to check for the consistency, stability and equivalence of moderating procedures across groups (Fern, 2001). Fern considers the coding scheme as critical. In order to ensure reliability of coding schemes, an independent professional clinical social worker was consulted and codes checked for independent assessment. Interrater analysis of data was conducted for thematic reliability, as well as feedback from participants.

Validity. Validity refers to assessing the findings of the measurement process (Hammersley, 1990). Internal validity of qualitative data is a complex issue, requiring that the representation of reality and feedback obtained from participants are recorded in a truthful way.

\section{Results}

Burnout assessment

The majority of teachers $(n=41 ; 65 \%)$ from both intervention and control groups identified with feeling burnout during the school year, all the time (30), or sometimes (11), being equally represented between men $(20,49 \%)$ and women. Burnout comments ranged from feeling this way at certain times of the year, such as the end of the week or end of the term and exam times, to a continuous feeling:

Always - forever want to give up teaching. Feel I can't cope in dealing with learners, feel I can't teach anymore. Always feel that I do not have enough time to relax, socialise etc. (I am) always physically/emotionally tired. (48 year old male teacher, working for 22 years)

The control group had the highest number of teachers $(n=15 ; 75 \%)$ who were always or sometimes burnt-out. This was followed by the TP intervention school $(n=11 ; 69 \%)$; and the TRE school with $(n=11 ; 65 \%)$. The TA intervention school had the lowest number of teachers who reported themselves to be burnt-out $(n=4 ; 40 \%)$.

The TA group had the smallest number of educators $(n=10)$ taking part in the intervention research, with $58 \%$ male $(n=6)$ and $42 \%$ female $(n=4)$. When reporting burnout, this group cited learner illdiscipline, departmental regulations, student apathy and attention level of learners as major stressors. With the control group, this was the only group to have more males than females. Seventy per cent were married $(n=7)$, with the balance single and one participant widowed. Fifty per cent $(n=5)$ were Christian, 40 per cent $(n=4)$ Muslim. This was the oldest group, with all participants over $40-60 \%$ being 40 - 50 and the remainder over 50 . Despite their age, this group had the least teaching experience of all the groups $-60 \%(n=6)$ had 10 to 20 years, $20 \%$ had less than 10 years' experience and $20 \%$ had 20 to 30 years.

Stressors. In line with the other two interventions, learner behaviour: "Ill-discipline of learners"; administration/workload: "Department regulations of teaching"; poor student work ethic: "student apathy" 
and illiteracy of learners: "Level of attention of students" were major stressors for TA teachers. In addition, they cited conditions at the school, parents who did not care or control their children, and having to teach a new subject area as major teaching stressors.

Emotional response - pre-TA intervention. Educators attending the TA intervention described a number of stressful events occurring at the school, which resulted in a variety of emotional responses. In one example, these emotions ranged from being angry, upset, stressed and anxious when a learner refused to take out his books. Stressors of having a learner shot and discovering a learner had been molested left an educator feeling shocked and traumatised, and he admitted he was still trying to cope with these events. Another educator described feeling disempowered when learners did not come to class with any materials like paper and scissors: "I feel powerless and hopeless".

When Grade 12 (17 years of age) learners came to class without completing an assignment, the educator felt angry, anxious and helpless. Another educator tried to disregard a learner "bunking" in class and not working. She felt anger, anxiety and helplessness. When a teacher felt under pressure during moderation, she withdrew, became quiet and was irritated with the learners. When a Grade 10 (15 years of age) class would not cooperate, the educator felt despondent, disappointed and worried.

Coping strategy - pre-TA intervention. In order to cope in stressful school situations, educators adopted a number of strategies, including a positive response: "I try not to give up, to approach things from a different angle. Stories that they can relate to help a lot". Some educators tried to use control with learners, while others became aggressive and threatening: "My reaction produced no positive result. I struggle with situations like these (throwing the learner out of class). "Another coping strategy was to disregard or ignore the disruptive learner, or to appeal to reason: "I felt out of control of my emotions and used reason to appeal to noisy matrics".

Competent classroom - pre-TA intervention. Good work ethic was considered the most important aspect of the competent classroom for teachers prior to attending the TA intervention: "Positive and hardworking learners". This is followed by well-equipped classrooms: "Conducive environment", competent teachers: "Well-prepared teacher", and a better context than the Cape Flats (Table 1).

\begin{tabular}{l|c|c}
\hline Code & No & $\%$ \\
\hline $\begin{array}{l}\text { Good work ethic: "Positive and } \\
\text { hard-working learners"; "Learners } \\
\text { willing to learn". }\end{array}$ & 6 & $43 \%$ \\
\hline $\begin{array}{l}\text { Well-equipped classroom: } \\
\text { "Conducive environment"; "More } \\
\text { resources". }\end{array}$ & 5 & $36 \%$ \\
\hline $\begin{array}{l}\text { Educator competency: "Well- } \\
\text { prepared teacher"; "I must be } \\
\text { positive". }\end{array}$ & 2 & $14 \%$ \\
\hline $\begin{array}{l}\text { Better environment: "Any class } \\
\text { outside of this environment". }\end{array}$ & 1 & $7 \%$ \\
\hline \begin{tabular}{l} 
Total \\
\hline
\end{tabular} & 14 & $100 \%$ \\
\hline
\end{tabular}

Table 1: Coding frame - Competent Classroom, PreTA Intervention

Emotional response - post-TA intervention. Some educators felt extremely positive and confident after the TA intervention: "Positive, confident, in control"; "I am positive and think before taking action". Although they also felt angry in stressful situations and negative emotions when challenged by learners, these reactions were processed rationally: "I felt understanding and in control"; "I did contracting with the parents and resolved the issue instead of shouting". Educators felt calm, grateful and empowered: "Thank you for empowering me as a father, husband, educator, manager and church leader with these skills. Your input, sacrifice, is (are) definitely valuable".

Coping strategy - post-TA intervention. Educators mostly drew on rational analysis and awareness to cope with stressful situations after the TA intervention: "I managed to calm the situation by thinking about it"; "I am positive and think before taking action". They used TA terminology to rationalise their behaviour in a stressful situation: "I feel empowered by the workshops with a range of insights which are all very helpful and these are/will add value to the way I interact with learners, parents and teachers". Educators felt more positive, confident and in control. They still experienced a variety of negative emotions in stressful situations, but with insight moved to a more able position. "I was disappointed, angry, disturbed" to "calm, positive, rational". When a non-TA participating teacher tried to choke a student in a fit of rage, the TA participant, who was also deputy principal, felt initially disappointed, and shocked, but then calm and 
rational, which allowed for a cool-off period with the parent, which he described as "working for the confrontation". He then felt "positive and good". With empowerment, educators became calm and empathetic towards learners.

Competent classroom - post-TA intervention. In line with these insights, the competent classroom was one in which there was primarily positive interaction between educator and learner: "By being a positive teacher in a classroom with visible positive signs, our learners will become positive too". There was an informed educator in the competent classroom, with implemented TA insights: "Giving positive strokes, trying to make lessons more interesting"; "A class that responds to contracting and knows its boundaries". Academic work was improved and there was learner support: "Learners must feel safe; educators need to create this atmosphere". The classroom environment should be conducive to learning, with adequate resources. (Table 2).

\begin{tabular}{|c|c|c|}
\hline Code & No & $\%$ \\
\hline $\begin{array}{l}\text { Positive interaction between } \\
\text { educator and learner: "By being } \\
\text { a positive teacher in a } \\
\text { classroom with visible positive } \\
\text { signs, our learners will become } \\
\text { positive too". }\end{array}$ & 7 & $28 \%$ \\
\hline $\begin{array}{l}\text { Informed educator: "One in } \\
\text { which educator implements } \\
\text { everything learnt in TA"; "A } \\
\text { class that responds to } \\
\text { contracting and knows its } \\
\text { boundaries". }\end{array}$ & 6 & $24 \%$ \\
\hline $\begin{array}{l}\text { Improved academic work: } \\
\text { "Learners should be focused, } \\
\text { study, strive for goals". }\end{array}$ & 5 & $20 \%$ \\
\hline $\begin{array}{l}\text { Learner support: "Learners } \\
\text { must feel safe; educators need } \\
\text { to create this atmosphere". }\end{array}$ & 5 & $20 \%$ \\
\hline $\begin{array}{l}\text { Conducive environment: "A } \\
\text { peaceful, warm atmosphere } \\
\text { conducive to learning". }\end{array}$ & 2 & $8 \%$ \\
\hline Total & 25 & $100 \%$ \\
\hline
\end{tabular}

Table 2: Coding Frame: Competent Classroom, Post-TA Intervention
Suggested improvements for TA intervention. Most comments were positive and suggested no improvements to the workshops: "Everything must stay the same"; "Continue the good work"; "Workshops on TA were interesting and fun compared with those offered by WCED. I'm going to miss it!" Educators then listed more time as a suggested improvement: "More time and days", "Go slower so PAC (Parent, Adult, Child ego states) elements can be properly understood". Some educators wanted more interaction/discussion around topics: "Make it more lively"; "Currently the interaction of everyone present - the informal yet formative nature of the sessions is very helpful"; "Was confused by transactions vs operations...needs to be better explained from the beginning". A few delegates wanted another venue: "Change the venue from the staff room to the library", while others wanted the workshops more relevant to their environment: "Relate the PAC to our learners in this environment".

Better materials were requested by some educators: "More detailed notes"; "Might show short video clips on observing different clues while detecting driver behaviour", while others wanted a different time for workshops: "Time/earlier...loved the morning workshop!" Several educators wanted the workshops to be more inclusive: "Currently we are having psychology chats and not including the five teachers who did not study psych!" "Do it with the whole school".

Impact of TA intervention. In TA workshops, teachers were given practical tools to deal with learners in the classroom. These ranged from contracting with classes to positive strokes, maintaining a structured discipline and encouraging attitude. Other practical tools were drivers, which explained behaviour, ego states, which gave behavioural insights and the drama triangle and winners' circle, which revealed unhealthy and healthy positions.

In using these tools, educators connected positively with others: "I can use it in any relationship - e.g. between me and my wife"; "(I) plan to use it in my small ladies' group". Educators gained self-help tools to cope in difficult situations: "It is imperative to value the input of all role players". With better selfunderstanding, educators feel more empowered to cope: "I discovered that I am good enough as I am"; "I plan to develop self-awareness with learners and parents" (Table 3). 


\begin{tabular}{|c|c|c|}
\hline Code & No & $\%$ \\
\hline $\begin{array}{l}\text { Tools for classroom: "I } \\
\text { discovered how to use } \\
\text { contracts in each of my } \\
\text { classes", "I suppose strokes } \\
\text { are important to everyone - } \\
\text { but especially our learners } \\
\text { given their context". }\end{array}$ & 27 & $38 \%$ \\
\hline $\begin{array}{l}\text { Connection with others: "I } \\
\text { can use it in any relationship - } \\
\text { e.g. between me and my } \\
\text { wife"; "Plan to use it in my } \\
\text { small ladies' group". }\end{array}$ & 19 & $26 \%$ \\
\hline $\begin{array}{l}\text { Self-help tools: "Self-help } \\
\text { tools"; "It was confirmed that I } \\
\text { have control over the life } \\
\text { position I assume and that } \\
\text { position will suggest to others } \\
\text { how they will respond to it"; } \\
\text { "It is imperative to value the } \\
\text { input of all role players". }\end{array}$ & 15 & $21 \%$ \\
\hline $\begin{array}{l}\text { Self-understanding: "I } \\
\text { discovered that I am good } \\
\text { enough as I am"; "I plan to } \\
\text { develop self-awareness with } \\
\text { learners and parents". }\end{array}$ & 11 & $15 \%$ \\
\hline Total & 72 & $100 \%$ \\
\hline
\end{tabular}

Summary of Coding Analysis

There were six main impacts of the interventions listed by educators: Intra-individual responses Impact 1: Body awareness; Impact 2: Calm and relaxation; Impact 3: Self-help tool; Impact 4: Selfunderstanding; and inter-individual responses; Impact 5: Tools for the classroom and Impact 6: Connection to others. Two further intra-individual impacts, Spiritual awareness (Impact 7) and Theoretical insights (Impact 8) were also listed.

TA supported inter-individual transactions, offering the most tools for the classroom and created a connection with the group. Self-help tools were gained and greater understanding of self resulted. However, there was neither body awareness nor calm and relaxation for educators in this intervention (Figure 1).

Thematic Analysis

Dominant themes. TA themes were grouped under personal, other (group, family) and classroom/school (See Table 4).

From a personal point of view, educators gained selfinsights, with improved emotional intelligence, being more in control of their emotions and better able to understand their own behaviours and recognise personal growth, leading to healthier lives and reduced stress:

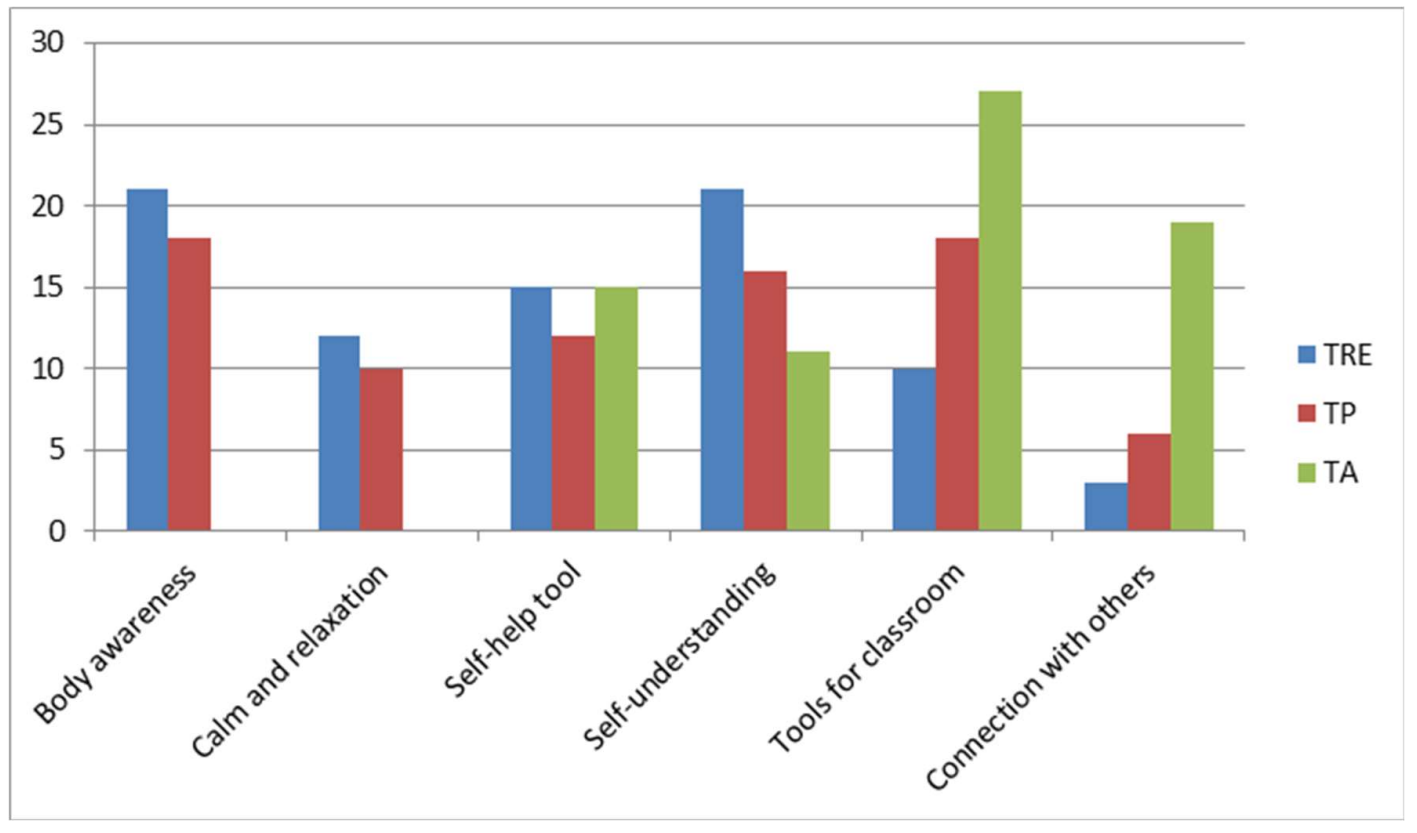

Figure 1. Summary of impact of interventions 


\begin{tabular}{|c|c|c|}
\hline Relationship with Self & Relationship with Others & Relationships with School \\
\hline $\begin{array}{l}\text { Gained self-insights: "When we fall in } \\
\text { a trap, immediately after that we } \\
\text { realise we have made a mistake". }\end{array}$ & $\begin{array}{c}\text { Deeper relationships with staff: "I am a } \\
\text { lot closer now to people within the } \\
\text { group because of the TA. In terms of } \\
\text { our understanding, I look at them and I } \\
\text { don't just see them as my colleagues, } \\
\text { as staff. I see much deeper, I see } \\
\text { people now". }\end{array}$ & $\begin{array}{l}\text { Stress reduction through improved } \\
\text { discipline: "Much of our stress results } \\
\text { from disciplinary problems, so this will } \\
\text { reduce our stressors". }\end{array}$ \\
\hline $\begin{array}{l}\text { Improved emotional intelligence: } \\
\text { "...You can actually pick up when you } \\
\text { are stressed, what emotions are } \\
\text { coming into play and you say: 'Listen, } \\
\text { here, get a hold of yourself', which is } \\
\text { very good”. }\end{array}$ & $\begin{array}{c}\text { Better staff understanding: "People } \\
\text { have a better understanding of each } \\
\text { other". }\end{array}$ & $\begin{array}{c}\text { More positive approach: "Now we } \\
\text { know, 'No, we are the ones that have } \\
\text { to be different because we are the } \\
\text { professionals', and by applying our TA } \\
\text { skills to our learners, we will eventually } \\
\text { have a positive influence". }\end{array}$ \\
\hline $\begin{array}{l}\text { Self-care: "I have learnt to relax, take } \\
\text { time for myself, take time for the } \\
\text { gym...and a lot of this is because of } \\
\text { what I have learnt here". }\end{array}$ & $\begin{array}{c}\text { Belief in group power: "What would } \\
\text { have happened if the whole staff was } \\
\text { doing this? What would have } \\
\text { happened if the whole school was } \\
\text { driving TA?" }\end{array}$ & $\begin{array}{l}\text { Change of attitude and improved } \\
\text { communication: "I can relate to } \\
\text { learners, I can talk to them...I remain } \\
\text { calm and inform them". }\end{array}$ \\
\hline $\begin{array}{l}\text { Gained skills with tools: "We have } \\
\text { picked up many skills and we have } \\
\text { many tools here that we can use in } \\
\text { different aspects of our lives". }\end{array}$ & $\begin{array}{l}\text { Improved communication skills: "I am } \\
\text { much more open to talking about it } \\
\text { (stress), especially to my wife, for } \\
\text { example, whereas before I never used } \\
\text { to talk about my problems". }\end{array}$ & $\begin{array}{l}\text { Greater understanding: "(It was) } \\
\text { empowering understanding the needs } \\
\text { of the next person". }\end{array}$ \\
\hline $\begin{array}{c}\text { Personal growth: Um, yes, with } \\
\text { awareness we used it (TA) but he, he } \\
\text { wasn't aware that I was going to use } \\
\text { my skills and neither did I know that he } \\
\text { was going to use his skills"; "Through } \\
\text { TA I have started to realise that } \\
\text { learners have problems and I have } \\
\text { become more aware and } \\
\text { sympathetic". }\end{array}$ & $\begin{array}{l}\text { Tools to understand behaviour: "I } \\
\text { mean I have always tried to do for my } \\
\text { family and friends things that worked } \\
\text { for them. And I realised subsequently } \\
\text { that I am the one to suffer because I } \\
\text { am doing everything for everyone else } \\
\text { and they are sometimes not even } \\
\text { demanding or expecting it". }\end{array}$ & $\begin{array}{l}\text { Improved emotional responses: “I } \\
\text { must say I am more relaxed in class. } \\
\text { Last year I was off for stress and it } \\
\text { was, like, I couldn't handle the children } \\
\text { but ever since I am busy with TA I am } \\
\text { quite in control of my emotions and I } \\
\text { am quite in control of the class". }\end{array}$ \\
\hline $\begin{array}{l}\text { Profound shifts: "I haven't been an } \\
\text { exemplary student going through the } \\
\text { notes again, but I have noticed I am } \\
\text { doing things better than what I am } \\
\text { used to doing things". }\end{array}$ & & $\begin{array}{l}\text { Educator is change agent: "I have } \\
\text { seen that I need to change towards } \\
\text { them and, as I have changed, they } \\
\text { have also so now it's a love/ove } \\
\text { relationship when it used to be a } \\
\text { love/hate relationship". }\end{array}$ \\
\hline $\begin{array}{l}\text { Calm and in control: "I am cool and } \\
\text { calm, even with my wife. My whole } \\
\text { perspective has been changed". }\end{array}$ & & $\begin{array}{c}\text { Competent class: "Has respect both } \\
\text { ways }(I+U+) \text { with acceptance of } \\
\text { diversity. The educator boosts learner } \\
\text { self-esteem and behaviour is governed } \\
\text { by contracts". }\end{array}$ \\
\hline
\end{tabular}

Table 4: Summary of TA Dominant Themes 
What is interesting is that when we are doing this course, when we fall in a trap, immediately after that we realise we have made a mistake - I was the rebellious child - and then we come to each other and confess, I did wrong, and so it shows that growth in our lives. (Male educator, 50 years old)

I have made personal decisions I should have made long ago, but realise because of TA I should have taken these steps, trust these steps and just do it. (Male educator, 44 years old)

What was very good was the stress drivers, I also liked that. When you can actually pick up when you are stressed, what emotions are coming into play and you say: 'Listen, here, get a hold of yourself', which is very good. I thoroughly enjoyed TA, I must say, every section of the work, from start to end, I found it very interesting (Female educator, 51 years old).

I have found that definitely, my stress levels have gone down quite a bit - in fact when I was at the doctor the last time (I have been on high blood pressure tablets for almost 10 years), he wanted to reduce them because my blood pressure was too low (laughter from the group) and he said I must come back in a month's time because he might consider lowering my medication" (Male educator, 48 years old).

Relaxation contributed to this reduced level of stress:

I have learnt to relax, take time for myself, take time for the gym...and a lot of this is because of what I have learnt here. For example, one of the ways that I dealt with stress was withdrawal and this causes all kinds of other problems. I don't get things done and I get behind in my school work and I recognised it as a survival strategy that is not working and I now recognise when I am doing this, I can see the warning lights.

Personal insights helped an educator to deal with a conflict around leadership in her church; she felt empowered and in control: "The impact on my personal life was very great. I was able to address certain issues that were bothering me and...l kept thinking, 'I'm OK, you're OK'... and I felt good, I felt excellent" (Female educator, 46 years old).

One teacher felt enskilled with many tools: "I think we have all been very fortunate to have been on this programme...We have picked up many skills and we have many tools here that we can use in different aspects of our lives" (Male educator, 50 years old). Another mentioned heightened levels of awareness: "The level of becoming aware of all of us has really improved...we are growing as a person and also we are very aware now...Like $H$ was saying, in a game maybe, how you can move out of the drama (triangle)" ( Female educator, 46 years old).

One educator tracked her journey in TA, saying she started out "extremely negatively" but that she became aware of profound shifts in herself:

I hate rudeness. If someone was rude I used to pounce. I don't pounce like I used to pounce (laughs). (Female educator, 50 years old)

She described how gradually she changed and started to look forward to TA:

I used to say sometimes, initially I would always say: "It's again TA today, oh, I'm tired," (others start to laugh) and as time went on, for the last couple of sessions (group laughs loudly) I haven't been saying that - I was actually looking forward to it. Before I, l'd not want to look at you (researcher) because you represented an afternoon session (group laughs loudly) and now it was nice to see you (laughs with the group). I could look you in the eye and I was happy to see you. And so, as time went along, I just felt that this is good for me, and I could see and in my personal life, I could see.

One educator missed the first few workshops and was encouraged to join by attending a few catch-up sessions. He expressed his appreciation and described the profound changes in him, feeling calmer and more in control:

So yes, thank you Sharon for hounding me, haunting me and victimising me (laughter from the group). I told Mr B, I am going to the meeting...Even getting here for a few workshops has changed me and I will carry that and I can progress more and maybe be a better person. (Male educator, 45 years old)

As a cognitive intervention, TA showed educators the power of knowledge:

Someone said some time ago that knowledge is power and that is true. Because when I hear other people acting out, I think: 'If only you knew what we know; then you won't act like that'. And sometimes it's laughable the way some professionals act. And that is only because of TA that we can see through different eyes. (Male educator, 50 years old)

From the group point of view, TA brought people closer:

I am a lot closer now to people within the group because of the TA. In terms of our understanding, I look at them and I don't just see them as my colleagues, as staff. I see much deeper, I see people now. (Male educator, 44 years old)

One educator said there was better understanding among his peers: "I think it is obvious that people 
have a better understanding of each other" (Male educator, 50 years old). Another was aware of group growth: "And I think, even we as a group, we can see in each other that we have really grown" (Female educator, 46 years old). Another educator noticed the divide between staff who had done TA and those who had not: "The other teachers pick up that we are different because we speak TA language. They say we don't know what you are talking about, and they sometimes sound envious, you know" (Female educator, 51 years old).

Appreciating the power of the "token" research group of TA educators, one teacher imagined the power of a greater number of people taking part: "Just imagine, we are just a token group doing TA. What would have happened if the whole staff was doing this? What would have happened if the whole school was driving TA?" (Male educator, 44 years old).

In terms of family, educators felt the insights learnt in the TA workshops helped them at home too. One educator said TA helped her to understand her teenage daughter better after the death of her husband:

Also with my daughter, because of the death of my husband, I had a really big struggle with her. And as Mrs $O$ was saying, with her I can really check out which ego state she is in and how to deal with her. Um, um and I can really say there is a big improvement by using positive strokes (Female educator, 46 years old).

Improved communication skills resulted in one educator being more able to talk to his wife after the workshops:

I am much more open to talking about it (stress), especially to my wife, for example, whereas before I never used to talk about my problems. She doesn't know anything about what I go through at school but now I tell her I feel this way because this has happened, that has happened...So definitely I am still learning and going through my notes and seeing where I can do something better...It has helped the marriage. (Male educator, 48 years old)

The drivers taught to educators were powerful tools to understand sources of stress. One educator learnt that she was a people pleaser, and this gave her insights on how to improve her relationships with her family and friends. Having had these insights, she describes how she is still struggling to modify old behaviour patterns:

Yes, I was shocked because I was a people pleaser, and it was so true. Because I thought, no I am not there, because I am in control with other people, but then I realised that when you enter my home, if you enter my home and you are going to sleep there, you will get the best. If you go to sleep and I know you are asleep, then I am going to take off my shoes and I tiptoe and I don't want to put on lights because I mustn't disturb you and l've been doing that for years...So that was also quite a shock to me, that I am still in this and I thought I was out of it (laughter). (Female educator, 50 years old)

Turning to TA effects in the school environment, the ability of the workshops to improve discipline meant it was a great stress reliever: "If we have positive behaviour, the discipline problems will drop. Much of our stress results from disciplinary problems, so this will reduce our stressors" (Male educator, 50 years old). He hoped that as part of Integrated Quality Management Systems being introduced, where teachers identify areas needing improvement, TA would then be taught to all educators as part of managing discipline in the classroom.

He continued to spell out how the positive TA approach helped educators:

As professionals and teachers, we come to a school where the learners have a certain way of doing things, influenced by the community, so some of us in the past expected the learners to be different when they are in school, in class. Now we know: "No, we are the ones that have to be different because we are the professionals," and by applying our TA skills to our learners, we will eventually have a positive influence.

Part of the change was improved communication skills, with a change of attitude: "I can relate to learners, I can talk to them...I remain calm and inform them - I wasn't loud, I wasn't rude, I wasn't aggressive" (Male educator, 45 years old). Many teachers shared the positive insights TA gave them to improve their behaviour with learners: contracts; cycles of development; the drama triangle were some of the tools mentioned:

I have learnt in the classroom you can now set up an agreement, a contract...that will still be my favourite part because from there I have learnt such a lot...Sometimes we as teachers get this idea that we are, agh, they are the students, we don't give them the same...platform, privilege because they are students, we've come to teach them, they have not come to teach us. So in that sense we don't treat them accordingly on the level you are supposed to...Now through the TA I can see you are emotionally immature, now I can handle you (laughter). No, no, no, I have learnt and I can identify. (Male educator, 44 years old)

As a teacher I have learnt such a lot. You treat them all the same...but hell no they are not, because according to TA they are still at certain stages in their 
life, (from) which they must move on. Through TA I have actually learnt that you treat an individual as an individual, and not as part of the group. Even though he is part of a group in the class, he is still an individual. That to me was an eye-opener - that is why I stayed in the (TA) group, I have not given up yet (laughter). (Male educator, 44 years old)

An interesting discovery was the drama triangle. Um, whenever something happens in front of you, or even when you are involved, it is being able to identify that this is a game and so then I can make a conscious choice whether I am going to take part in this game or not, or whether I am going to move into the winner's circle. When your eyes are opened about these things, you see it a lot - in the staff room, in the classroom, you see the games, you see positions people take and, and I am just glad that we are now equipped to realise these things and not fall into the emotional trap, er again". (Male educator, 50 years old).

Another tool which had a great impact on educators was the concept of positive strokes, where they learnt that their behaviour positively influences learners:

The positive strokes were for me the best; it has such an impact on our learners. I complimented a girl on her smile and I said, 'As good as your smile is today, give me a good answer to the question I have asked now', and she gave me the correct answer and an even bigger smile and so for me that was important. I think the children are picking up on my behaviour as well in the classroom, so their reaction is also more positive. It seems that our relationship is more positive as a result of TA and I think it has its inroads, good inroads, so I like that. (Female educator, 51 years old)

An educator recalled how giving an appropriate positive stroke to a learner made him feel empowered:

At the end of a function one of our kids came up to me and said: 'Sir, are you proud of me?' and I immediately understood that he wanted to be stroked, that's all. Very innocent, and I could understand that immediately. (It was) empowering understanding the needs of the next person. (Male educator, 50 years old)

Other teachers spoke about improved emotional intelligence in the classroom, which led to relaxation and less stress:

Let's say the learners are rude, then I gave it to them because I hate when they are rude to one another or in my presence. But now I find I would rather defuse that situation and if I do get angry with somebody, it's not angry at you, but at the action. I would stop afterwards and make you say what the situation was all about. (Female educator, 50 years old)

My relationship with the children....we've got a good relationship, a much better relationship than we used to have, and also I have gained a lot. (Female educator, 40 years old)

A dominant theme in the TA focus group was the teacher capable of being the change agent in the school, which was an important realisation in terms of the competent classroom:

I used to be very angry with this particular class because of their behaviour, not being attentive, not being what it should be. But as times have changed, I have seen that I need to change towards them and, as I have changed, they have also so now it's a love/ove relationship when it used to be a love/hate relationship. I was also not OK and they were not OK, but now we are both OK and that to me is good.

Many teachers have the attitude that they can do nothing with the learners, they are from $x x$, there is nothing good about them. And I think this is quite a comfortable excuse we are making. What TA has highlighted for me is that this is an excuse for us to do nothing. And TA shows us that there is something we have to do, that we can do and that we should do. And we can make a difference. The moment we look at the learners and are comfortable to do something, they are normal people and we can do something to change them" (Male educator, 48 years old).

Summary of thematic data analysis

In analysing dominant themes in TRE, TP and TA interventions, the different impact of these approaches became evident. In the relationship of educators with themselves, with their peer group and families and with the learners in the classroom, powerful insights and realisations were gained. In the case of TRE, teachers were aware of becoming grounded and centred and felt in touch with their bodies, releasing stress and burnout on a physical level. They felt emotional benefits of being calm and in control and changed perceptions of self-concept and thinking processes. In the case of TP, there was a feeling of becoming calm and controlled, with renewed energy, emotional intelligence and powerful group connection, reducing feelings of isolation and thus assisting in stress and burnout reduction. In the case of TA, psychological insights into their own and learner behaviour reduced the greatest reported cause of stress: discipline in the classroom. Educators thus felt more in charge and were able to become change agents in their schools. 


\section{Discussion}

Benefits of TA

After the TA intervention, educators had powerful insights and gained realisations that improved relationships with themselves, their peer group, families and learners in the classroom. By acquiring social psychological tools, they understood learner behaviour better and saw themselves as the professional change-agents in the classroom. They were also able to apply these tools to themselves, better understanding their emotional and cognitive responses and were able to modify their behaviour in appropriate ways. They gained in self-confidence, with an ability to be in control and plan for the future.

Relationships in the classroom changed from love/ hate to love/ love, or in the language of TA to $(\mathrm{I}+, \mathrm{U}+)$ - I'm OK, you're OK (Berne, 1961). The definition of a competent classroom after the intervention was one of mutual respect between educator and learner, where the educator boosted learner self-esteem and where behaviour was governed by contracts.

\section{Challenges of TA}

Initially it was not easy to convince educators to attend workshops when their timetables were filled with classes of undisciplined learners, meetings, administrative and marking workloads and this was especially in the case of TA, where workshops involved sitting for extended periods of time, with long discussions which required focus and attention. There were no opportunities for any relaxation techniques, as in TRE or TP interventions, and educators admitted that they were hesitant and resistant to begin with. This was reflected in the low number of educators who participated in the research. However, as the workshops progressed, educators quickly began to appreciate the power of TA to make profound changes in their lives and especially the classroom, so an enthusiastic engagement replaced the negativity, which was an initial major challenge to overcome.

Some educators wanted topics to be discussed in more depth to be better understood, and others wanted more variety of presentation than a flipchart and lecture. More application in the classroom was requested by one educator, with greater discussion and interaction. Several educators wanted the workshops to be more inclusive, involving all the school, as a divide was created amongst staff between those who attended and understood TA and those who did not.

\section{Conclusions of TA}

With many educators responding negatively to Department of Education workshops, it required something special to attract and retain participants in workshops in high-risk secondary schools, where there was little time to include outside activities into busy teaching and meeting schedules. However some headteachers, including the one at the TA school, were prepared to include this stress programme into the curriculum. At first TA seemed intellectually challenging and demanding to understand, but educators soon began to appreciate the insights gained and started to notice changes in themselves and their colleagues. In the end, there was much laughter and animated discussions around relationships and psychological games, especially in the school and classroom.

TA provides powerful tools for educators to manage learner discipline and should be introduced into the curriculum at teacher training institutions to teach basic social psychology. Alternatively, it could be introduced into schools as part of staff development. International programmes for teachers and learners are available in South Africa, where Proficiency Awards (IDTA 2014) are given to encourage educators and children to apply what is learnt and produce portfolios of evidence. This supervised application could ensure that TA is implemented, understood and practised for the benefit of both educators and learners in challenging and traumatic classroom contexts.

\section{Limitations}

In considering the limitations of the mixed-methods approach, there is little written to guide the researcher through the process (Creswell, 2009). In addition, there is little advice to be found how a researcher should resolve discrepancies that occur between the two types of data. Because the methods are unequal in their priority, this approach can result in unequal evidence within a study, which may be a disadvantage when analysing results. Significant differences both within and between groups in levels of stress and burnout were recorded in all three interventions in the statistical analysis part of the study (Johnson, 2013) with qualitative interpretation of benefits and challenges for the teachers synergistic with these quantitative results.

Sample group selection and size could be considered limitations of the study, as random selection was not possible with teachers working in different schools and only available on specific days and times due to demanding and varying school schedules. Also the ethical voluntary requirements of the study allowed teachers to elect not to attend interventions as in the case of the control group, despite higher levels of burnout in the majority $(n=15$; $75 \%$ ) of this sample. Groups varied between 10 and 20 delegates, which are small samples of participants. 


\section{Conclusions}

Three interventions, based on the physical, emotional and cognitive responses to threat, were utilised in this qualitative and quantitative mixedmethods study of teacher stress and burnout in highrisk schools. The interactional effect of these three responses was evident in all interventions; there were emotional and cognitive effects in the bodybased intervention; physical and cognitive responses in the emotionally-orientated intervention and, as described in this paper, physical and emotional benefits in the cognitively-orientated intervention.

Coding analysis focused on the intra- and interindividual TRE, TP and TA tools that had an impact on teachers in their efforts to cope with stress and burnout. Focus group interviews gave thematic insights into physical, emotional and cognitive responses to stress and burnout interventions on the individual, interpersonal and organisational levels and revealed new perspectives on classroom competency, with teachers taking more responsibility for discipline in the classroom, their greatest stressor.

This study indicated that the interactional effect of physical, emotional and cognitive responses to stress and burnout can be effectively mediated by TRE, TP and TA. All three interventions offered teachers in high-risk schools physiological, affective and cognitive tools to dealing with threat and trauma, assisting with stress and burnout reduction and facilitating renewed insights into classroom competency. Depending on teacher orientation to healing, a combination of interventions, or an intervention of personal choice, could be utilised in high-risk schools in South Africa to reduce the stress and burnout suffered by teachers.

Dr Sharon Johnson is a post-doctoral fellow at the Psychology Department of Stellenbosch University, South Africa and can be contacted at shajohnson@mweb.co.za

\section{References}

Bauer, M. (2000). Classical content analysis: a review. In M. Bauer and D. Gaskell (eds.), Qualitative researching with text, image and sound: A practical handbook for social research (pp.131-151). London: Sage Publications Ltd.

Benjamin, L. (2010). The impact of trauma and learning: $A$ basic guide for educators. Cape Town: Case Publications.

Berceli, D. (2007). Evaluating the effects of stress reduction exercises. Unpublished doctoral dissertation, Arizona State University, USA.
Berne, E. (1961). Transactional analysis in psychotherapy. New York: Grove Press.

Berne, E. (1962). Classification of positions. Transactional Analysis Bulletin, 1 (3), 23.

Berne, E. (1964). Games people play. New York: Grove Press.

Berne, E. (1966). Principles of group treatment. New York: Oxford University Press.

Berne, E. (1972). What do you say after you say hello: The psychology of human destiny. New York: Grove Press.

Cane, P. M. (2000). Trauma healing and transformation. California: Capacitar International.

Capazorio, B., \& Thakali, T. (2012, November 4). Major matric shake-up on the cards. Weekend Argus, p.1.

Cook, T.D., \& Campbell, D.T. (1979). Quasiexperimentation: Design and analysis issues for field studies. Chicago: Rand McNally.

Corey, M.S., Corey, G., \& Corey, C. (2010). Groups: Process \& practice (8th ed.). Belmont, CA: Brooks/Cole.

Creswell, J.W. (2009). Research design: Qualitative, quantitative, and mixed-methods approaches (3rd ed.). Thousand Oaks, CA: Sage Publications, Inc.

Cummings, J.L., \& Mega, M.S. (2003). Neuropsychiatry and behavioural neuroscience. New York: Oxford University Press.

Day, A.L., \& Livingstone, H. A. (2001). Chronic and acute stressors among military personnel: Do coping styles buffer their negative impact on health? Journal of Occupational Health Psychology, 6, $348-360$.

Dewe, P.J., O'Driscoll, M.P., \& Cooper, C.L. (2010). Organisational stress: A review and critique of theory, research and applications. London: Sage Publications.

Drego, P. (1981). Ego-state models. TASI Darshan, 1 (4).

English, F. (1976). Differentiating victims in the drama triangle. TA Journal, 6 (4), $384-386$.

Ernst, F. (1971). The OK coral: the grid for get-on-with. TA Journal, 1 (4), 231 - 240.

Fern, E.F. (2001). Advanced focus group research. Thousand Oaks, California: Sage Publications, Inc.

Freudenberger, H. J., \& Richelson, G. (1980). Burnout. New York: Bantam Books.

Gold, Y., \& Roth, R.A. (2003). Teachers managing stress and preventing burnout: The professional health solution ( $2^{\text {nd }}$ ed.). London: Routledge Farmer.

Hammersley, M. (1990). The dilemma of qualitative method: Herbert Blumer and the Chicago tradition. London: Routledge. 
Hartley, R. (2012, October 21). Education is the foundation for change. Sunday Times, p. 4.

Holtzkamp, J. (2010). The development and assessment of a family resilience-enhancement programme. Doctoral dissertation, Stellenbosch University.

Human Sciences Research Council. (2005). Study of demand and supply of educators in SA public schools. Pretoria: Education Labour Relations Council.

IDTA (Institute of Developmental Transactional Analysis (2014) Transactional Analysis Proficiency Awards http://www.instdta.org/ta-proficiency-awards.html accessed 11 November 2014

Jalamba, N (2009) personal communication, May 22.

Jansen, J. (2012, January 7). Matric razzmatazz conceals sad reality. Weekend Argus, p.4.

Johnson, S.M. (2010). Transpersonal practices as prevention intervention for burnout amongst HIV/Aids coordinator teachers. Unpublished master's dissertation, Stellenbosch University.

Johnson, S.M. (2013). Impact of stress and burnout interventions on educators in high-risk secondary schools. Doctoral dissertation, Stellenbosch University.

Johnson S. M. and A.V. Naidoo. (2010) Transpersonal practices as prevention intervention for burnout among HIV/Aids coordinator teachers. South African Journal of Psychology 43(1): 59-70.

Kahler, T., \& Capers, H. (1974). The miniscript. TA Journal, 4 (1), 26 - 42.

Kaminer, D., \& Eagle, G. (2010). Traumatic stress in South Africa. Johannesburg: Wits University Press.

Karpman, S.B. (2007). The drama triangle. Paper presented at the 2007 International Transactional Analysis Association (ITAA). Retrieved on June 6, 2012 from http://karpmandramatriangle.com/pdf/thenewdramatringles .pdf

Kokkinos, C.M. (2007). Job stressors, personality and burnout in primary school teachers. British Journal of Educational Psychology,77, 229-243.

Lazarus, R.S., \& Folkman, S. (1984). Stress, appraisal and coping. New York: Springer Publishing Company, Inc.

Leon, J. (2000). The role played by hardiness and attributional style in the dynamics of stress and coping processes amongst teachers. Unpublished master's thesis, University of Cape Town.

Marvasti, A. (2004). Qualitative research in sociology. London: Sage Publications Ltd.

MacLean, P.D. (1990). The triune brain in evolution: Role of the paleocerebral functions. New York: Plenum Press.

McElheran, M. (2013). Trauma change resilience.

Retrieved on 20th September, 2013 from

http://youtu.be/P8nMgY5dkTs.
McKenna, J. (1974). Stroking profile. Transactional Analysis Journal, 4 (4) 20 - 4.

Millward, L. (2012). Focus groups. In G.M. Breakwell, J.A. Smith \& D.B. Wright (Eds.), Research methods in psychology (4th ed.) (pp. 411-439). London: Sage Publications.

Morgan, D.L. (1997). Focus groups as qualitative research (2nd ed.). Thousand Oaks, CA: Sage Publications Ltd.

Munusamy, R. (2013, February 15). Jacob Zuma's ailing state of the nation. Daily Maverick. Retrieved from http://www.guardian.co.uk/world/2013/feb/15/south-africazuma-sona.

Ringel, S., \& Brandell, J.R. (2011). Trauma: Contemporary directions in theory, practice and research. Thousand Oaks, CA: Sage.

Silverman, D. (2011). Interpreting qualitative data ( $4^{\text {th }}$ ed.). Thousand Oaks, CA: Sage Publications Ltd.

South African Press Association (2013). SA teachers set absentee record. Retrieved February 26, 2013 from http//www.news24.com/South Africa/news.

Steiner, C. (1971). The stroke economy. TA Journal, 1 (3), $9-15$.

Stewart, I. (1992). Eric Berne. London: Sage Publications Ltd.

Talob, E.R. (1994). Using TA to enhance adjustment in Filipino college students. Transactional Analysis Journal, 24(3), 198-205.

Travis, J.W., \& Ryan, R.S. (2004). Wellness workbook (3rd ed.). California: Celestial Arts.

Van der Kolk, B.A. (2007). Foreword.In R.C. Scaer (Ed.). The body bears the burden: Trauma, dissociation and disease (2nd ed.) (pp. ix - xv). New York: Norton.

Van Wyk, M. (2006). Emotional-social competencies that enhance wellness in teachers: An exploratory study. Unpublished master's thesis, Stellenbosch University.

Waghid, Y., \& Davids, N. (2013). Citizenship, education and violence. Rotterdam: Sense Publishers.

Wilkerson, K. (2009). An examination of burnout among school counsellors guided by stress-strain-coping theory. Journal of Counseling and Development, 87(4), 428-437.

Wood, T., \& McCarthy, C. (2002). Understanding and preventing teacher burnout. Eric Digest. Retrieved November 11, 2008 from http://www.ericdigests.org/2004I/burnout.htm

Yakovlev, P.I., \& Lecours, A.R. (1967). The myelogenetic cycles of regional maturation of the brain. In A. Minkowski (Ed.), Regional development of the brain in early life. Edinburgh: Blackwell Scientific Publications 